\title{
The physiology of learning: strategies clinical teachers can adopt to facilitate learning
}

\author{
Satid Thammasitboon ${ }^{1}$ (i) • Paul L. P. Brand ${ }^{2,3}$ (D) \\ Received: 28 January 2021 / Revised: 16 February 2021 / Accepted: 21 March 2021 / Published online: 29 March 2021 \\ (C) The Author(s) 2021
}

\begin{abstract}
Almost all pediatricians working in a hospital or office environment have teaching responsibilities to learners such as medical students and residents. Although teaching and supporting learning in a busy work environment imposes challenges to clinical teachers, these clinical settings provide an ideal setup for experiential learning, learning from daily experiences with patients. Advances in the science of learning derived from various fields have informed us how adults learn best. Many techniques and strategies based on this "physiology of learning" have shown their educational values in everyday pediatric practice. This article outlines how clinical teachers can create the conditions to optimize experiential learning for individual or a group of learners. We highlight practical implications of educational theories and evidence-based educational practices for clinical teachers seeking to enhance their teaching effectiveness. These include promoting active learning and engaging learners in deliberate practice; retrieval of knowledge and prior experiences to enhance motivation; supporting a psychologically safe learning environment; helping learners to set goals; fostering collaborative learning; structuring teaching to link it to authentic roles and tasks; and customizing content to individual learners.

Conclusion: Applying adult learning principles in everyday teaching activities will support busy pediatricians to be successful in their tasks as clinical teachers, and contribute to work satisfaction.

\section{What is Known:}

- Most pediatricians provide clinical teaching to medical students and residents, but few have had formal training in educational techniques.

- Learning from clinical experiences (experiential learning) is of key importance to becoming and maintaining a competent pediatrician.

What is New:

- This review presents an up-to-date overview of the physiology of learning, i.e., how people learn.

- Knowledge of the principles of how people learn helps pediatricians shape their clinical teaching effectively and contribute to their work satisfaction.
\end{abstract}

Keywords Clinical teaching $\cdot$ Adult learning principles $\cdot$ Learning environment $\cdot$ Active learning $\cdot$ Deliberate practice

Series Editor: Paul Brand

This article is part of the Topical Collection on The Art and Science of Clinical Pediatric Education

Paul L. P. Brand

p.l.p.brand@isala.nl

Satid Thammasitboon

satidt@bcm.edu

1 Intensive Care Medicine Section and Center for Research, Innovation and Scholarship in Medical Education (CRIS), Texas Children's Hospital, Baylor College of Medicine, Houston, TX, USA

2 Isala Academy, Department of Medical Education and Faculty Development, Isala Hospital, Zwolle, The Netherlands

3 Lifelong Learning Education and Assessment Research Network (LEARN), University of Groningen and University Medical Center, Groningen, The Netherlands
Scenario:

Each morning after handover, there is a planned 30-min teaching session to discuss an interesting case from the handover with a group of learners (i.e., three interns, one upper-level resident, a nurse practitioner, and a fellow). This morning, most discussion during handover was about the use of high-flow nasal oxygen (HFNO) in an infant with bronchiolitis. How do you approach this teaching session with this group with different levels of learners? 


\section{Introduction}

Providing teaching and learning in a busy work environment imposes challenges to clinical teachers. At the same time, these busy clinical settings provide an ideal setup to learn from the daily experiences with patients that are encountered by medical students, interns, and residents. This process of learning from relevant experiences is called experiential learning $[1,2]$. According to Knowles' adult learning principles, the participants in experiential learning are self-directed learners who can identify their own learning needs; they use their experience as a basis for their learning; they are oriented to learning things that are immediately applicable; and they prefer material that is relevant to their everyday practice [3]. Over the past decades, advances in the science of learning derived from cognitive psychology, neuroscience, sociology, anthropology, educational science, and behavioral economics have informed us how people learn best. Many techniques and strategies based on this "physiology of learning" have shown their educational values in authentic learning environments such as everyday pediatric practice [4].

We describe here how clinical teachers can create the conditions to optimize experiential learning for individual or a group of learners. We highlight practical implications of educational theories and evidence-based educational practices for clinical teachers seeking to enhance their teaching effectiveness.

\section{Using the "physiology of learning" in clinical teaching practice}

The integration of Knowles' principles with Kolb's experiential learning model allows for an easy-to-follow guide of effective clinical teaching to support learning in medical students and residents (Fig. 1). We illustrate this with examples how the steps in this model can be executed by busy clinical teachers. This list is by no means exhaustive; it is intended to serve as a starting point for interested readers to explore the suggested literature, and to try out new approaches based on the educational theory provided.

The principles and activities outlined in the conceptual model in Fig. 1 align closely with the kind of things medical learners in the clinical workplace mention with when asked to reflect on good learning experiences [5]. We summarize the ten principles of adult learning clinical teachers can apply to enhance the effectiveness of their teaching in Table 1.

Kolb's experiential learning cycle (center) describes the sequence of activities to enable learning for adult learners (outer boxes). In this model, a concrete experience is used to activate the learner's prior knowledge and to identify a knowledge (or skills, or attitude) gap the learner wishes to fill. Through reflection on the experience, the learner constructs new concepts about the knowledge gap, seeks additional new knowledge from external sources, and determines their application. The learner then applies the learned knowledge in new situations, which provides a new concrete experience to learn

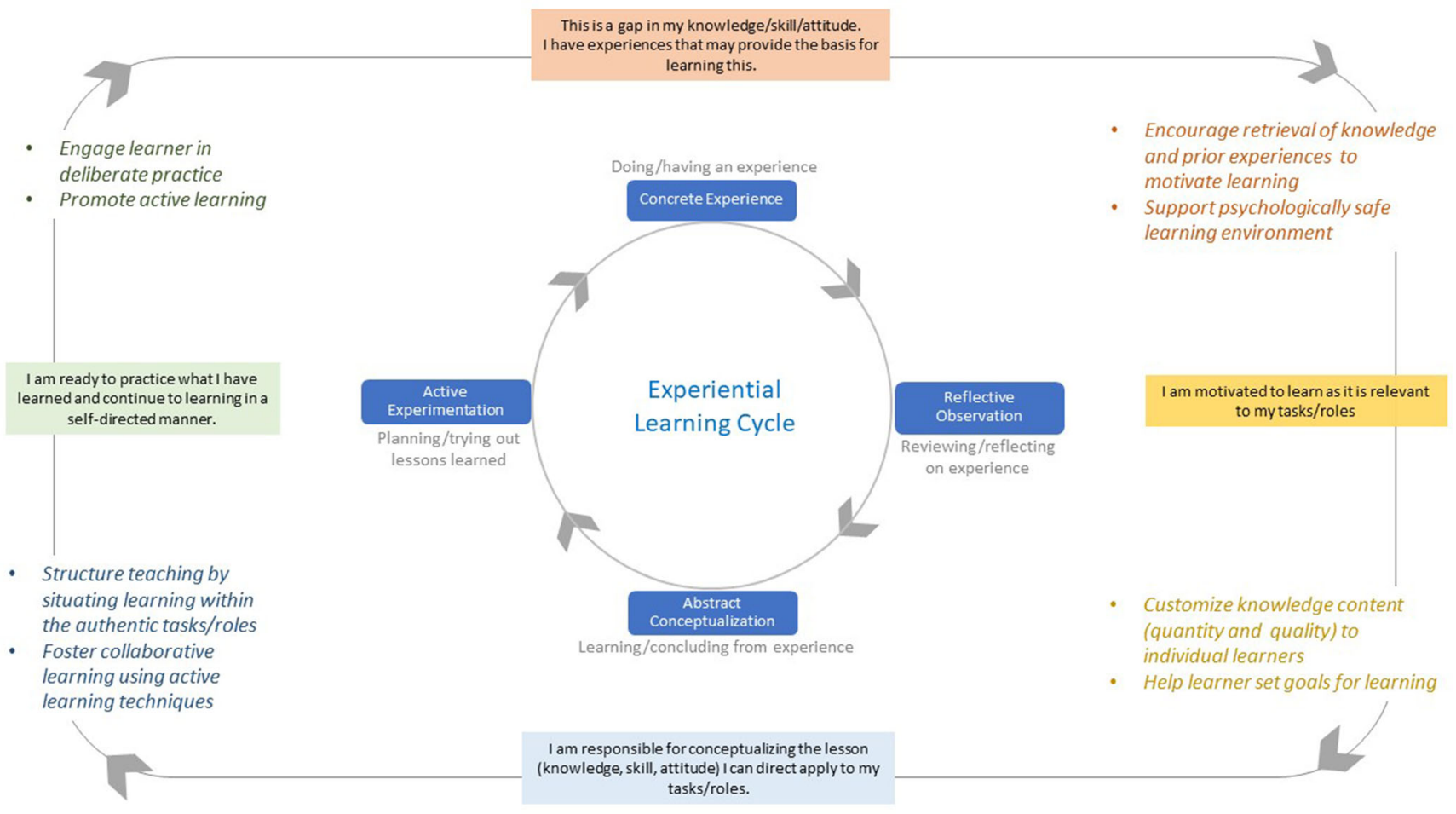

Fig. 1 The conceptual model of the "physiology of learning" 
from, and starts a new cycle of learning. Different learners may have different preferences at which activity they prefer to enter the learning cycle, but effective learning is supported best by moving through all four activities. Advances in learning sciences offer evidence-based teaching practices (colored texts with adult learning principles) that clinical teachers can employ to enhance their workplace teaching, and to increase the effects of their teaching on their learners.

\section{Encourage retrieval of knowledge and prior experiences to} motivate learning It is helpful to assess what learners already know as this will help both individual learners and the teacher identify gaps in knowledge, skills, or attitudes. Assessing learners' current knowledge is particularly useful in the setting with multiple levels of learners, so teachers can customize teaching at a level appropriate for the learners. This can be achieved by using a quiz or self-assessment testing prior to a teaching session, or by Socratic questioning during the teaching encounter. The term "Socratic questioning" does not refer to the "pimping" technique in which a supervisor poses a barrage of questions to learners to demean them, but describes an approach to questioning that probes learners' current understanding to discover contradictions and gaps of understanding, allowing them to express their uncertainties and doubts safely, without the risk of being disparaged, and expand their knowledge [6]. If done properly, teachers can help individual learners activate their prior knowledge or experience to serve as a foundation for the learning session that follows in a homogenous group of learners. Appropriate questioning creates a challenge that prompts learner engagement, particularly if it is sufficiently challenging or difficult to enable the learners to take the next step in their learning.

Support a psychologically safe learning environment There is a fine line between effective questioning for inquiry and pimping. A set of rapid-fire questions can easily induce fear and stress among learners. A person's emotional state plays a significant role in psychological processes of learning [7]. A right

Table 1 The principles of adult learning, supporting effective teaching in the clinical workplace

Set one or more clear learning objectives $[6,7]$

Address learners' intrinsic motivation to learn by aligning your learning aims to theirs [15]

Make sure that the content is relevant to the learners [8]

Use learners' previous experiences to promote reflection and make the topic relevant [15]

Pitch the teaching at the right level of previous knowledge [11]

Structure your teaching session effectively [11]

Show enthusiasm for the topic and for teaching [12]

Involve the learners actively $[6,9,10]$

Promote reflection by asking questions [14]

Provide your learners with repeated constructive feedback [13] amount of stress motivates learning, but too much stress or fear compromises learning. Psychological safety has been shown to be critical to learning [8]. When learners sense interpersonal trust and mutual respect, they feel comfortable to engage in inquiry and discourse freely. Activating existing knowledge and experiences also allows teachers to convey the critical message that learners' viewpoints and contributions are valued and respected, and teachers can customize the teaching points or learning materials accordingly.

Example: You could initiate the discourse by questioning interns as a group how the HFNO differs from regular low flow oxygen by nasal canula, allowing each intern to contribute to the answer. Inviting more experienced team members like residents to share their personal experiences or what they have read on the topic can enhance the discourse. The quality of the contributions from these individuals reflects how much they know without putting anyone on the spot.

Customize knowledge content to individual learners To motivate learners, teachers can highlight how the materials are applicable and relevant to learners' roles and the related tasks. Relevance of knowledge may not always be obvious to novice learners. The assessment from the previous step helps teachers to select teaching points related to the clinical experience encountered. Avoid clinical teaching via a "canned talk"-it will not support clinical experiential learning. Consider the delivery of content in "small chunks" and minimize extraneous loads (e.g., teaching tangential topics or discussing very rare diseases) to reduce cognitive load and optimize learning [9]. Guiding learners to valid and reliable resources for learning assignments allows them to focus on mastering the knowledge rather than wasting cognitive efforts on distinguishing highquality from low-quality resources. As mentioned earlier, stress or fear can affect learning as negative emotions are also extraneous cognitive load to learning.

Help learners set goals for learning Helping learners to set learning goals or providing clear learning objectives for them promotes learners' motivation and knowledge acquisition and retention [10]. A goal that is too easy or too tedious can be demotivating. To build a motivating learning session, teachers must set a challenging and yet achievable goal, inquire an explicit commitment from learners from the outset, provide intermittent feedback, and adjust or break down the goals (e.g., short-term and long-term goals) according to task complexity [11].

Foster collaborative learning using active learning techniques Learning is facilitated when the learner processes the 
information, not just listens to it [12]. Instead of "spoon feeding" the whole knowledge content, effective teachers engage their audience actively, by asking questions and by providing sufficient support to help learners build on prior knowledge, and move towards new concepts, skills, or understandings. Similar to the scaffolding of a building, teachers can provide a temporary structure that supports their learners in constructing their own new concepts or ideas, by providing basic concepts, content structure, or learning strategies. Scaffolding and active learning techniques help to reduce frustration and intimidation when learners engage in a difficult topic or task, and encourage further self-directed learning.

Example: You could provide some background knowledge, e.g., on the pathophysiology of bronchiolitis, and then ask an advanced learner to teach basic respiratory physiology (e.g., lung capacity and volumes) or to discuss the most relevant clinical endpoints to be used in HFNO clinical trials, before assigning different learners to explore the topic further (e.g., types of respiratory failure for interns, present results of systematic reviews of clinical trials or of the validity and applicability of evidence in clinical practice guidelines for bronchiolitis for the upper-level resident), and to report back later that day. You may consider guiding learners to high-yield educational resources (e.g., books, online videos) to facilitate efficiency of learning.

\section{Structure teaching by situating learning within authentic} tasks/roles Learning is a social activity which should always be situated or attached to the clinical context in which it occurs [13]. In addition, learners will always adapt their learning behavior to what they perceive to be the social norms of the medical profession. Clinical learning environments are perfect to role model collaborative learning wherein each member contributes to and learns from one another to construct meaningful new knowledge. Teachers can foster collaborative learning through active learning strategies (e.g., think-pair-share, debate, problem-solving task) $[14,15]$. Such collaborative learning within a clinical department will help to shape the development of the learner's professional identity as a team member [16]. As the current generation of learners grow up playing games and have gamer's mindset (e.g., adopt a challenge, prefer options, cultivate connectedness), the use of game elements (e.g., by using a reward system of points, levels, or leaderboards) stimulates engagement and allows learners to explore, fail, and learn within safe boundaries [17].
Example: To induce active learning, you could divide learners into teams to study and debate about the effective use of HFNO in different situations. If you wish, you can incorporate game elements like using a "challenge of the day" for point collection as individuals or teams. In addition to solving the case at hand, you can bring in other real clinical cases to compare and contrast the large variations in clinical manifestations.

Engage learners in deliberate practice Acquiring competence in complex skills can be promoted through deliberate practice, a process of systematic repeated exposure to the tasks of performing the complex skills, supported by repeated structured constructive feedback [18] Teachers who want their learners to use the knowledge they transferred during a teaching episode will therefore challenge the learners to try it out in practice, reflect on the experience, and ask for feedback.

Promote active learning Deliberate practice is, in fact, the repeated progression through Kolb's learning cycle (Fig. 1). Complex and integrated skills like those involved in communicating with patients [19], or applying evidence-based medicine [20], cannot be learned in a single standalone teaching exercise, but require deliberate practice. Effective clinical teachers therefore promote active learning by encouraging learners to set new learning aims, by keeping an interest in the learner's application of newly learned knowledge and skills, by providing constructive feedback repeatedly, and by setting a role model of lifelong learning themselves.

Example: During the 30-min teaching session after handover, you employed some of the strategies outlined in the examples above, to engage the learners actively and to stimulate discussion. You showed enthusiasm, both for the teaching topic and the teaching as an activity. At the end of the 30-min session, you let the learners summarize what they have learned and what they will apply in practice. You provide them with reading materials for further exploration, and you set a date for the follow-up teaching session in which you will discuss what they have read, thought of, and tried out.

Authors' Contributions ST designed the setup of the paper and of the figure, reviewed the literature, decided on the content, wrote the initital draft and edited the manuscript. PB developed the idea for the paper, designed the setup of the paper, reviewed the literature, decided on the content, and edited the manuscript.

Data availability N/A

Code availability N/A 


\section{Declarations}

\section{Ethics approval N/A \\ Consent to participate N/A}

Consent for publication Both authors consent to the publication of the manuscript.

Conflict of interest The authors declare no competing interests.

Open Access This article is licensed under a Creative Commons Attribution 4.0 International License, which permits use, sharing, adaptation, distribution and reproduction in any medium or format, as long as you give appropriate credit to the original author(s) and the source, provide a link to the Creative Commons licence, and indicate if changes were made. The images or other third party material in this article are included in the article's Creative Commons licence, unless indicated otherwise in a credit line to the material. If material is not included in the article's Creative Commons licence and your intended use is not permitted by statutory regulation or exceeds the permitted use, you will need to obtain permission directly from the copyright holder. To view a copy of this licence, visit http://creativecommons.org/licenses/by/4.0/.

\section{References}

1. Kolb DA. Experiential learning. Englewood Cliffs, NJ: PrenticeHall; 1984. https://doi.org/10.1002/job.4030080408

2. Yardley S, Teunissen PW, Dornan T (2012) Experiential learning: AMEE Guide No. 63. Med Teach 34:e102-e115. https://doi.org/ 10.3109/0142159X.2012.650741

3. Knowles M. The adult learner: a neglected species. Houston, TX, USA: Gulf Publishing Company; 1973 1973.https://doi.org/10. 1177/074171367402500106

4. Gooding HC, Mann K, Armstrong E (2017) Twelve tips for applying the science of learning to health professions education. Med Teach 39:26-31. https://doi.org/10.1080/0142159X.2016.1231913

5. Lake FR (2004) Teaching on the run tips: doctors as teachers. MedJAust 180:415-416

6. Stoddard HA, O'Dell DV (2016) Would Socrates have actually used the "Socratic method" for clinical teaching? J Gen Intern Med 31:1092-1096. https://doi.org/10.1007/s11606-016-3722-2

7. McConnell MM, Eva KW (2012) The role of emotion in the learning and transfer of clinical skills and knowledge. Acad Med 87: 1316-1322. https://doi.org/10.1097/ACM.0b013e3182675af2
8. Edmondson AC, Higgins M, Singer S, Weiner J (2016) Understanding psychological safety in health care and education organizations: a comparative perspective. Res Hum Dev 13:65-83. https://doi.org/10.1080/15427609.2016.1141280

9. Mayer RE (2010) Applying the science of learning to medical education. Med Educ 44:543-549. https://doi.org/10.1111/j.13652923.2010.03624.x

10. Huang PH, Haywood M, O'Sullivan A, Shulruf B (2019) A metaanalysis for comparing effective teaching in clinical education. Med Teach 41:1-14. https://doi.org/10.1080/0142159X.2019.1623386

11. Locke EA, Latham GP. New developments in goal setting and task performance. New York: Routledge; 2013. https://doi.org/10.4324/ 9780203082744

12. van der Vleuten CP, Driessen EW (2014) What would happen to education if we take education evidence seriously? Perspect Med Educ 3:222-232. https://doi.org/10.1007/s40037-014-0129-9

13. Durning SJ, Artino AR (2011) Situativity theory: a perspective on how participants and the environment can interact: AMEE Guide no. 52. Med Teach 33:188-199. https://doi.org/10.3109/ 0142159X.2011.550965

14. Smith MK, Wood WB, Adams WK, Wieman C, Knight JK, Guild N, Su TT (2009) Why peer discussion improves student performance on in-class concept questions. Science 323:122-124. https://doi.org/10.1126/science.1165919

15. Krupat E, Richards JB, Sullivan AM, Fleenor TJ Jr, Schwartzstein RM (2016) Assessing the effectiveness of case-based collaborative learning via randomized controlled trial. Acad Med 91:723-729. https://doi.org/10.1097/ACM.0000000000001004

16. Sawatsky AP, Santivasi WL, Nordhues HC, Vaa BE, Ratelle JT, Beckman TJ, Hafferty FW (2020) Autonomy and professional identity formation in residency training: a qualitative study. Med Educ 54:616-627. https://doi.org/10.1111/medu.14073

17. Nicholson S. A RECIPE for Meaningful Gamification. In: Reiners $\mathrm{T}$, Wood L, editors. Gamification in education and business. New York: Springer International Publishing; 2014. p. 1-20. https://doi. org/10.1007/978-3-319-10208-5 1

18. Ericsson KA (2008) Deliberate practice and acquisition of expert performance: a general overview. Acad Emerg Med 15:988-994. https://doi.org/10.1111/j.1553-2712.2008.00227.x

19. Wouda JC, van de Wiel HB (2013) Education in patient-physician communication: How to improve effectiveness? PatientEducCouns 90:46-53. https://doi.org/10.1016/j.pec.2012.09.005

20. Draaisma E, Bekhof J, Langenhorst VJ, Brand PLP (2018) Implementing evidence-based medicine in a busy general hospital department: results and critical success factors. BMJ Evid Based Med 23:173-176. https://doi.org/10.1136/bmjebm-2018-110895

Publisher's note Springer Nature remains neutral with regard to jurisdictional claims in published maps and institutional affiliations. 